\title{
Impact of Alloy Composition and Thermal Stabilization on Martensitic Phase Transformation Structures in CuAIMn Shape Memory Alloys
}

\author{
Uwe Arlic ${ }^{a}{ }^{-}$, Hennadiy Zak ${ }^{b}$, Bernd Weidenfeller ${ }^{c}$, Werner Riehemann ${ }^{a}$ \\ anstitute of Materials Science and Engineering, Clausthal University of Technology, D-38678 \\ Clausthal-Zellerfeld, Germany \\ ${ }^{b}$ Institute of Metallurgy, Clausthal University of Technology, D-38678 Clausthal-Zellerfeld, Germany \\ 'Department of Materials Science, Institute of Electrochemistry, Clausthal University of Technology, \\ D-38678 Clausthal-Zellerfeld, Germany
}

Received: September 30, 2017; Revised: May 14, 2018; Accepted: June 08, 2018

\begin{abstract}
Alloys of CuAlMn are known as cheap, high strength shape memory alloys with an excellent damping capacity within their austenitic-martensitic phase transformation, compared to alloy systems like NiTi, CuZnAl or $\mathrm{MnCu}$. But CuAlMn alloys have disadvantage due to generation of voids by a high shrinkage which further increases the existing proneness to stress cracks during rapid cooling. Alloying grain refining elements improves the stress crack resistance and enables a wide range of rapid quenching parameters which are needed to control the temperature of martensitic phase transformation. Additionally, the elements itself influence the in- or decreasing of the phase transformation temperature and the SMA effects. Furthermore, some of these elements can reduce the internal friction indirectly by decomposing areas of metastable martensite into its stabilized forms, where no transformation occurs. This thermic stability can be calculated by the concentration of valence electrons in a unit cell. The proneness to ageing is controlled by multistep heat treatments. Annealing and rapid quenching into the area of martensitic phase transformation maximize the generation of point defects. A high amount of point defects contradicts the negative effect of pinning. It also preserves the material from extreme brittleness. The influences of these effects are shown at single cantilever bending beams by elastic strain amplitude $(\varepsilon=12 \mathrm{E}-4)$ depending measurements of internal friction at natural frequency along the ageing at room temperature $(293 \mathrm{~K}$ ) up to $2500 \mathrm{~h}$. The samples are annealed at $1123 \mathrm{~K}$ for $15 \mathrm{~min}$

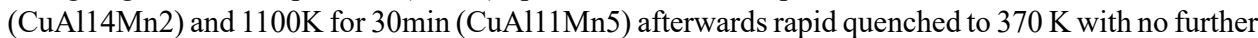
thermic stabilisation. The base alloy of CuAl14.1Mn2.0Ni1.9Fe 0.4 had an internal friction measured as logarithmic Decrement $(\delta)$ of 0.155 and 0.11 after $2500 \mathrm{~h}$ of ageing at RT. The phase transformation is located between $284 \mathrm{~K}$ and $352 \mathrm{~K}$, measured by DSC. The alloy of CuAl11.1Mn5.5Zn2.9Ni2.1 had a logarithmic decrement of 0.31 and diminish continuously to 0.12 after $2500 \mathrm{~h}$ of ageing at RT. The phase transformation is located between $287 \mathrm{~K}$ and $318 \mathrm{~K}$.
\end{abstract}

Keywords: CuAlMn, SMA, HIDAMET, internal friction, martensitic phase transformation.

\section{Introduction}

Shape memory alloys exhibit high damping properties mainly due to thermoelastic martensitic phase transformations, which are related to the energy loss by the movement of the parental martensite planes, martensite variant interfaces and twin boundaries. Key to maximize these effects belong to the stabilization of the intermetallic high temperature $\beta$-phase and its low temperature successors transformation window near the intended application temperature ${ }^{1,2}$. The austenitic $\beta$-phase arranged to the lower order system $\beta_{1}$ (L21; Cu2AlMn) and martensitic phase stabilization of (unstable) $\beta_{3}^{\prime}$ (18R) to (stable) $\gamma_{3}^{\prime}(2 \mathrm{H})$ ratio can be adjusted by quenching and the amount of aluminium (Al) and manganese $(\mathrm{Mn})^{3,4,5} \cdot$ In $^{6,7}$ heat treatments above $1073 \mathrm{~K}$ and quenching are considered to improve the damping capacity. Small quenching rates and also low temperature ageing pins (by point defects) the system by increasing the amount of $\gamma_{3}^{\prime}$ which leads to reduced SME, damping capacity and increased martensite start $\left(\mathrm{M}_{\mathrm{S}}\right)$ temperatures ${ }^{8}$. High amounts of $\mathrm{Al}$ and $\mathrm{Mn}$ are known for lowering $\mathrm{M}_{\mathrm{S}}$ temperature and exhibit excellent SME (above 12.8 wt. $\% ~ \mathrm{Al}^{9}$ ), but limits usability due to extreme brittleness in polycrystalline systems ${ }^{4,8,10,11}$. Zinc and nickel can be used as less effective substitutes for $\mathrm{Al}$ to reduce the $\mathrm{M}_{\mathrm{S}}$. But if their amount got to high, they tend to increase the prowess to ageing at RT and brittleness ${ }^{8,12,13}$. The lately researched elements $\mathrm{Be}, \mathrm{Ag}, \mathrm{Mg}$ show some interesting influence in controlling the phase transformation temperatures and aging stabilisation, too ${ }^{12,14-17}$.

A method of adjusting Cu-based materials by means of the alloying composition can be achieved by considering the valence electron concentration (e/a). As described in $9,18,19$, materials with a value below 1.45 exhibit very good mechanical properties but a higher $\gamma^{\prime}{ }_{3}$ to $\beta_{3}^{\prime}$ ratio and thus only a limited SME and damping behaviour. If the concentration in the composition rises above 1.51, very pronounced SME 
can occur, but the material tends to be brittle due to the previously mentioned $\mathrm{Al}$ problem.

This work will present two alloys and their room temperature (RT) ageing influencing their damping capacity measured by amplitude depended internal friction (ADIF).

\section{Experimental Procedure}

Both alloys were designed with a low e/a (1.357 for $\mathrm{P} 1$ and 1.359 for $\mathrm{P} 2$ ) to enable a regular cast production process. Higher ratio of e/a results in high amounts of various cast related defects like heat cracks or cavities as seen at Figure 1. The samples were prepared by induction melting

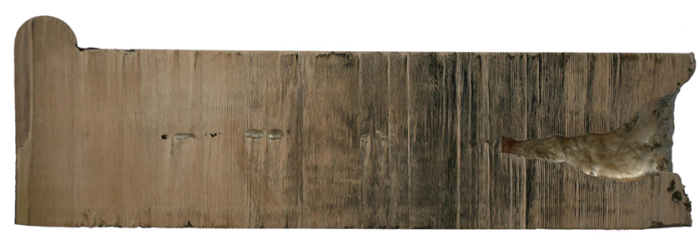

$50 \mathrm{~mm}$

Figure 1. Typical example of cavities at a large volume casting sample of $\mathrm{P} 1$

in an argon atmosphere. The permanent steel ingot mold was preheated to $573 \mathrm{~K}$. The cast temperature exhibited $1423 \mathrm{~K}$ The chemical composition of the alloys shown in Table 1 was determined by an inductively coupled plasma optical emission spectrophotometer (PlasmaQuant PQ 9000 Elite, Analytik Jena AG, Jena, Germany).

The obtained cylindrical ingots had diameters of $15 \mathrm{~mm}$ and a length of $140 \mathrm{~mm}$ and were machined to rectangular bending beams of $97 \mathrm{~mm}$ length, $10 \mathrm{~mm}$ width, and $2 \mathrm{~mm}$ thickness.

In this study, two types of heat treatments will be presented. The heat treatment parameters, listed in Table 2, were refined through variable previous measurements on both materials. Their transformation temperatures were determined by differential scanning calorimetry (F402 Phoenix, Netzsch Gerätebau, Selb, Germany) at heating and cooling rate of $5 \mathrm{~K} / \mathrm{min}$. The masses of both samples are: P1 (140,43 mg) and P2 (135.74 mg).

Quenching directly to RT caused extreme brittleness (instant fracturing during handling) due to high internal stress arising during heat treatment and phase transformation.
Table 2. Heat treatment conditions.

\begin{tabular}{lc}
\hline Designation & Heat Treatment Condition \\
\hline HT1 & 1123K for 15 minutes, quenched by hot water \\
& till $373 \mathrm{~K}$ \\
HT2 & 1103K for 30 minutes, quenched by hot water \\
& till $373 \mathrm{~K}$ \\
\hline
\end{tabular}

Ductility can be preserved by an increase of the quenching medium temperature above the phase transformation temperature ${ }^{6}$. The material will be kept at boiling temperature for 3 minutes. Afterwards it is cooled down to RT naturally by surrounding atmosphere.

The microstructures were studied by optical microscopy and scanning electron microscopy. The grain size analysis was carried out by the linear-intercept method after etching the polished surface with an acid ferric chloride solution (10 $\mathrm{g} \mathrm{Fe} 3 \mathrm{Cl}, 25 \mathrm{ml} \mathrm{HCl}$ and $100 \mathrm{ml}$ distilled water $)^{20}$.

Tensile tests were carried out after heat treatment in a UTS Zwick testing machine (Zwick GmbH \& Co. KG, Ulm, Germany). The test is normed by DIN EN ISO 6892-1 with the sample diameter of $6 \mathrm{~mm}$ and measuring length of 30 $\mathrm{mm}$. An initial strain rate was $2.5 \mathrm{E}-3 \mathrm{~s}^{-1}$.

The strain related amplitude depended internal friction (ADIF) was investigated as logarithmic decrement (IF) $\delta$ of vibrations free decay in the bending mode at room temperature $(293 \mathrm{~K})$. The specimens were clamped into single cantilever bending beam configuration and excited by an electromagnetic excitation to vibrations with the resonant frequency at the maximum strain amplitude of 12E-4. The used damping measurement system is described at detail in ${ }^{21}$.

\section{Results and Discussion}

\subsection{Phase transformation temperatures}

The DSC measurements show the phase deformation temperatures of both sample types after their initial heat treatments. Figure 2a shows the P1 sample in the HT1 condition. Instead of a single peak like the P2 alloy (see Figure 2b), two peaks appear. It indicates the appearance of a multistage martensite austenite transformation $\left(\beta_{3}^{\prime}(18 \mathrm{R}) \rightarrow \gamma_{3}^{\prime}(2 \mathrm{H}) \rightarrow \beta_{1}(\mathrm{~L} 21)\right)$ during the heating process ${ }^{3,22-25}$. During the cooling route, no separated $2 \mathrm{H}$ peak is shown. The burst like peaks in the slope (appearing between $295 \mathrm{~K}$ and $325 \mathrm{~K}$ ) are $18 \mathrm{R}$ transformations, which are activated discontinuously due to the additional energy loss during the previous $2 \mathrm{H}$ transformation ${ }^{26}$. The $\mathrm{P} 2$ alloy shows, as anticipated in ${ }^{4}$, no such system due to its lowered $\mathrm{Al}$ content (3 wt.\%). The $\beta^{\prime 3}$ martensite is predominant ${ }^{11}$.

Table 1. Chemical composition of the investigated alloys.

\begin{tabular}{lcccccccc}
\hline Designation & $\mathrm{e} / \mathrm{a}$ & \multicolumn{5}{c}{ Chemical Composition (wt.\%) } \\
\hline & & $\mathrm{Cu}$ & $\mathrm{Al}$ & $\mathrm{Mn}$ & $\mathrm{Zn}$ & $\mathrm{Ni}$ & $\mathrm{Fe}$ \\
\hline P1 & 1.357 & 81.24 & 14.13 & 2.03 & & 1.91 & 0.39 \\
$\mathrm{P} 2$ & 1.359 & 77.47 & 11.17 & 5.54 & 2.90 & 2.11 & 0.51 \\
\hline
\end{tabular}



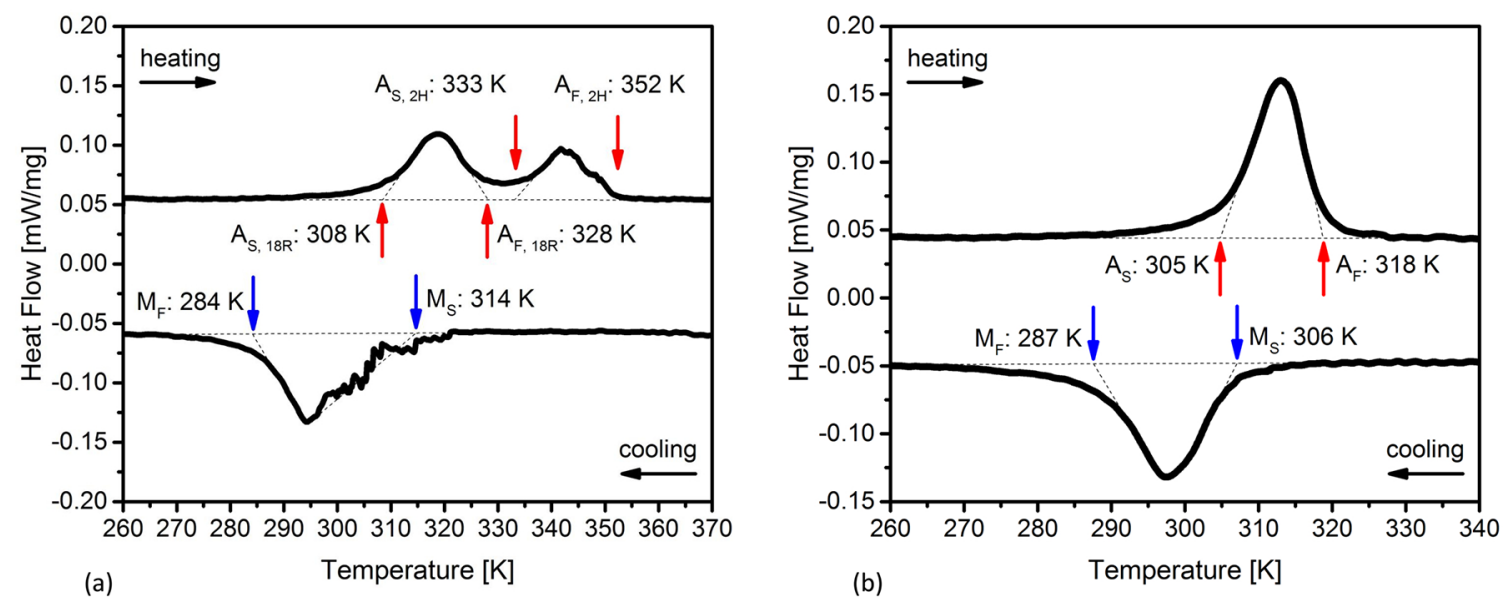

Figure 2. Phase transformation temperatures of P1 (a) and P2 (b) samples tested by DSC

The most effective damping is achieved when the samples temperature stays within both peaks of martensite generation $\left(\mathrm{M}_{\mathrm{S}}\right.$ to $\left.\mathrm{M}_{\mathrm{F}}\right)$ and its decomposing $\left(\mathrm{A}_{\mathrm{S}} \text { to } \mathrm{A}_{\mathrm{F}}\right)^{27}$. For $\mathrm{P} 1$ sample,

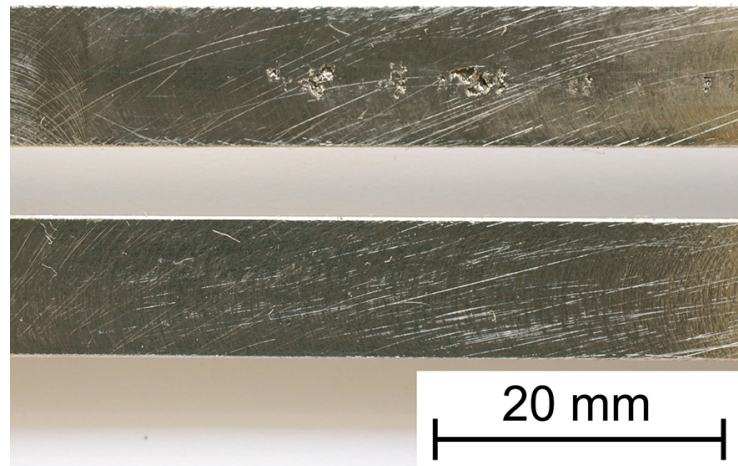

Figure 3. Example of material samples with cavities (P1, above) and a free of cavities (P2, below)

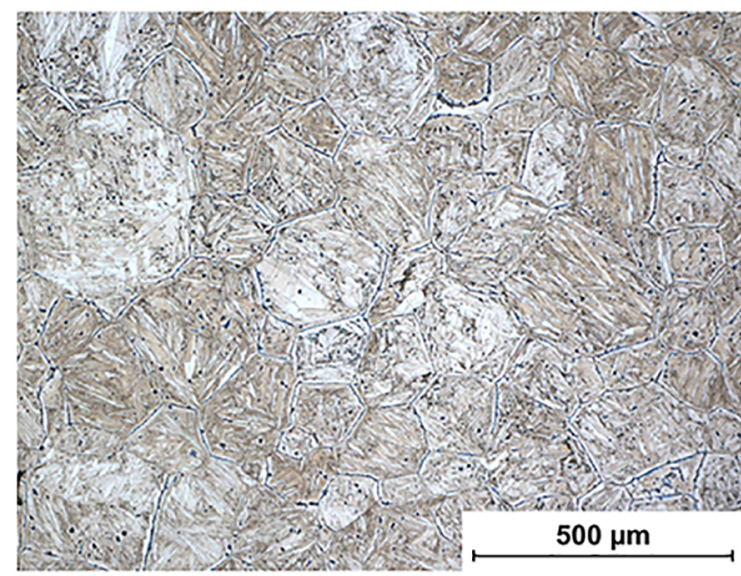

(a) these range of temperature resides between $294 \mathrm{~K}$ and 320 $\mathrm{K}$. The range in P2 sample is within $297 \mathrm{~K}$ and $312 \mathrm{~K}$.

\subsection{Structure}

The upper specimen (P1) in Figure 3 contains many cavities. In comparison, the material of P2 sample (bottom microphotograph in Figure 3) had no such defects.

Examples of the microstructure at RT of both types of materials are shown in Figure 4a for P1 and b for P2 samples. The average grain size of $\mathrm{P} 1$ is about $104 \mu \mathrm{m}$. The grain size variations correspond well to the normal distribution. P2 sample consists of grains with an average size of 155 $\mu \mathrm{m}$. On the other hand, the grain size of P2 sample is not uniform; 36 vol.\% of the grains have a size between $500 \mu \mathrm{m}$ and $250 \mu \mathrm{m}$ and $53 \mathrm{vol} . \%$ tend to be smaller than $60 \mu \mathrm{m}$. Grains with the same sizes are organised in homogeneous clusters resulting in the local averages areas which strongly differs from the calculated mean size of the overall material. The reason for this structure can be the addition of $\mathrm{Zn}$

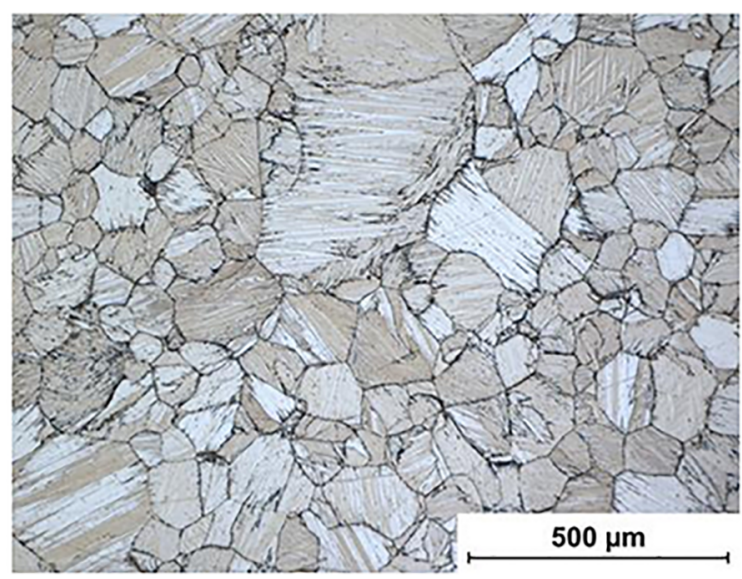

(b)

Figure 4. Microstructure of $\mathrm{P} 1$ (a) and $\mathrm{P} 2$ (b) samples, measured at RT and taken from centre and parallel to the long axis of each ingots 


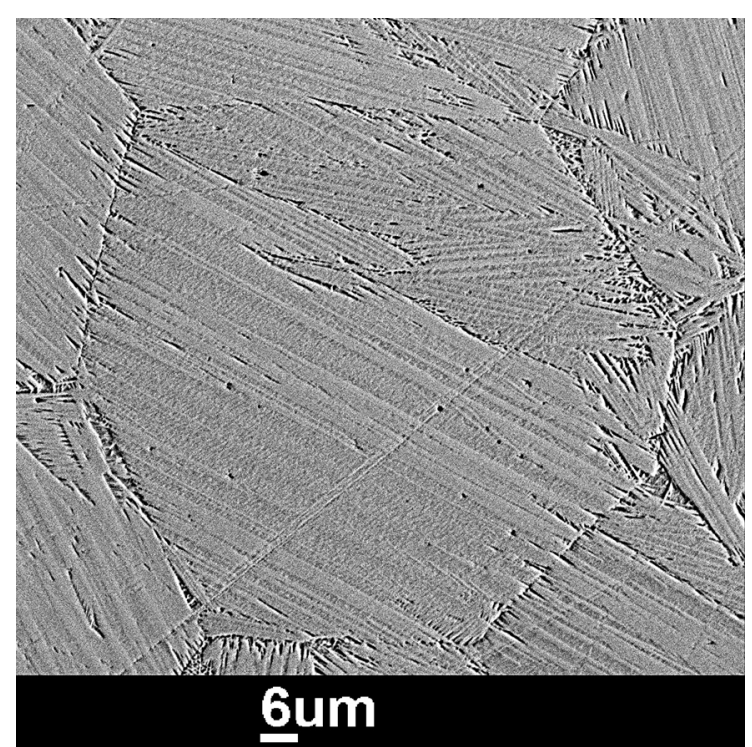

Figure 5. Rudimentary martensite microstructure of P2 sample measured by SEM at RT

and $\mathrm{Ni}$ the elements (both known as grain refiners) and their non-uniform distribution during the casting process. Figure 5 shows a close up of P2 sample recorded by SEM. Where martensite resides near the grain boundaries and as a larger area lancet structure at the upper part of the shown grain. But the martensite structure exists only partially as in anticipated by the results presented in Figure $2 b$.

\subsection{Internal friction}

The amplitude dependency of the logarithmic decrement or internal friction (IF) is shown in Figures 6a for P1 and b for P2 samples, respectively. Each graph consists of two areas which deliver unique information on the strain independent and dependent parts of the IF. These components can be expressed as

$$
\delta=\delta_{0}+\delta H(\varepsilon)
$$

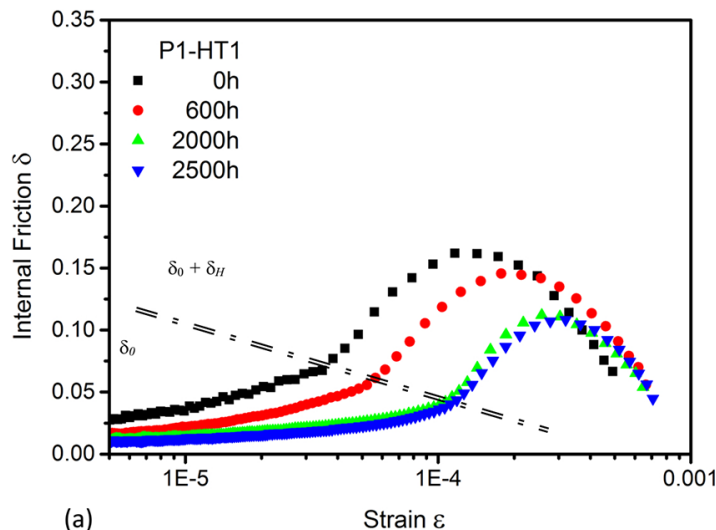

where $\delta_{0}$ is the amplitude independent (or slightly dependent) component, found at lower amplitudes and $\delta_{H}$ amplitude dependent component. While several mechanisms may contribute to the amplitude independent component (dislocations, grain boundaries, etc.) the strain amplitude dependent component $\delta_{H}$ is caused in materials with the SME predominately by the occurrence of the transformation process in the martensite phases. As it follows from Figure 2 the maximum of the IF may be expected above the testing temperature at RT. The initial IF of the $\mathrm{P} 2$ sample $(\delta=0.31)$ is twice higher compared with the $\mathrm{P} 1(\delta=0.155)$ system. But both alloys have a similar IF after ageing at RT. Ageing $1500 \mathrm{~h}$ caused a linear decrease of $\delta$ down to a stable value of $\delta=0.115(\mathrm{P} 1)$ and $\delta=0.12$ (P2). As it is demonstrated in Figure 6a, the P1 sample decreased mainly its $\delta_{0}$ component down to the minimum value of 0.035 while the $\delta_{H}$ component remained nearly constant. It indicates that the martensite in the $\mathrm{P} 1$ sample is resistant against ageing. The $\mathrm{P} 2$ sample decreased mainly the $\delta_{H}$ component during ageing while the $\delta_{0}$ component was only influenced slightly. After $1500 \mathrm{~h}$ this loss of $\delta_{H}$ stabilises at 0.12 (Figure 6b). Comparing the behaviour of $\delta_{H}$ in P1 and P2 samples an interesting accordance appears. Both martensite related IF shares, stable their losses at nearly same amount of $\delta$ after a nearly identical time of ageing. This can be interpreted that

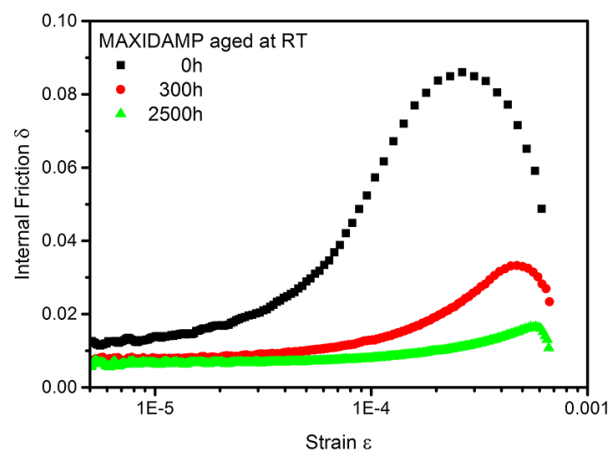

Figure 7. Strain amplitude dependency of the internal friction measured in MAXIDAMP ${ }^{\circledR}$

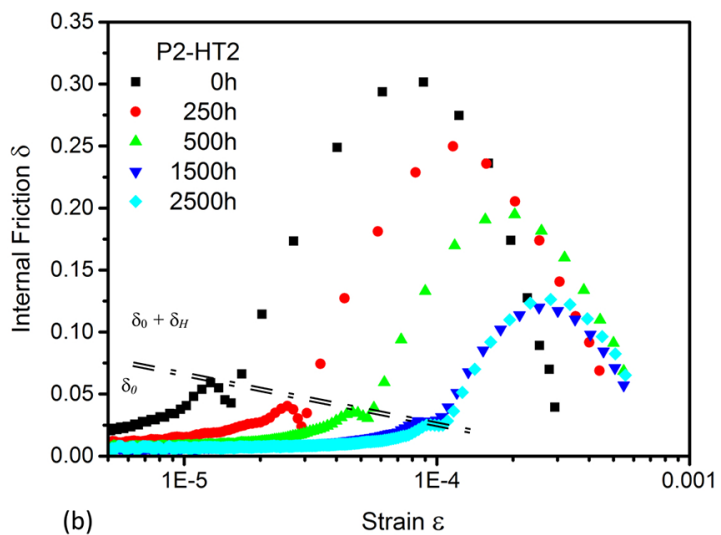

Figure 6. Strain amplitude dependency of the internal friction measured for P1 (a) and P2 (b) samples 
$\beta_{3}^{\prime}$ martensite decomposes to $\gamma_{3}^{\prime}$ by ageing and the phase transformation window increases above the experiments temperature of $\mathrm{RT}^{3,4,5}$. If compared with results obtained on the commercial available alloy of MAXIDAMP ${ }^{\circledR}$ (Patent: DE $102005035709 \mathrm{~A} 1$, of Technology) measured in the same experimental conditions (see Figure 7) both tested alloys show superior damping behaviour.

\subsection{Mechanical properties}

Both alloys P1 and P1 exhibit also good but not superior tensile properties compared with commercial alloys. P1 sample showed an average tensile strength $\left(\mathrm{R}_{\mathrm{m}}\right)$ of $557 \mathrm{MPa}$ and strain $\left(\mathrm{A}_{5.65}\right)$ of $2.8 \%$. P2 sample showed an average tensile strength $\left(\mathrm{R}_{\mathrm{m}}\right)$ of $351 \mathrm{MPa}$ and strain $\left(\mathrm{A}_{5.65}\right)$ of $1.85 \%$. Due to brittle fracture of both alloys at RT the tensile tolerance resides within $20 \%$. As for comparison the properties of MAXIDAMP $®$ are tensile strength $\left(\mathrm{R}_{\mathrm{m}}\right)$ between $600-650$ $\mathrm{MPa}$ and strain $\left(\mathrm{A}_{5}\right)$ of $8-18 \%$.

\section{Conclusions}

A CuAlMn-based HIDAMET SMA was produced with standard permanent mold casting. The alloys composition and their heat treatments were optimised with the aim to find their long-time stable states. The investigated properties of the $\mathrm{CuAlMn}$ samples leading to the following main conclusions:

- Valence electron concentration proves as a good control mechanism for alloy composition. Undesirable amounts of Al can be substituted by similar effective elements like $\mathrm{Zn}$ or $\mathrm{Ni}$ in terms of phase transformation temperatures and internal friction.

- The damping capacity ( $\delta$ ) stabilizes well in both materials at a high level above 0.1 after roughly $1500 \mathrm{~h}$ aging.

- The modified alloy composition proved far better at the casting process. The margin of casting errors is significantly reduced.

- The increasing of $\mathrm{M}_{\mathrm{S}}$ temperature could not be properly suppressed. The phase transformation window left the targeted operational temperature of RT

- The tensile strength and ductility are in the P2 alloy much worse. Both properties drop by almost $37 \%$.

The optimised material shows interesting and good damping and casting behaviour. Our research showed that the SMAs containing $\mathrm{Zn}$ and $\mathrm{Ni}$ have very good potential for various applications. For an improvement of mechanical properties and stabilisation of the $\mathrm{M}_{\mathrm{S}}$ temperature further research will be necessary.

\section{References}

1. Otsuka K, Wayman CM, eds. Shape Memory Materials. Cambridge: University Press; 1999.
2. Van Humbeeck J, Stoiber J, Delaey D, Gotthardt R. The High Damping Capacity of Shape Memory Alloys. International Journal of Materials Research. 1995;86(3):176-183.

3. Kainuma R, Takahashi S, Ishida K. Thermoelastic martensite and shape memory effect in ductile $\mathrm{Cu}-\mathrm{Al}-\mathrm{Mn}$ alloys. Metallurgical and Materials Transaction: A. 1996;27(8):2187-2195.

4. Mallik US, Sampath V. Influence of aluminum and manganese concentration on the shape memory characteristics of $\mathrm{Cu}-\mathrm{Al}-$ Mn shape memory alloys. Journal of Alloys and Compounds. 2008;459(1-2):142-147.

5. Wang Q, Han F, Cui C, Bu S, Bai L. Effect of ageing on the reverse martensitic phase transformation behaviours of CuAlMn shape memory alloy. Materials Letters. 2007;61(30):5185-5187.

6. Mielczarek A, Riehemann W, Vogelgesang S, Zak H, Tonn B. Amplitude Dependent Internal Friction of CuAlMn Shape Memory Alloys. Key Engineering Materials. 2006;319:45-52.

7. Wang Q, Han F, Hao G, Wu J. Influence of heat treatment on the damping behaviour of a Cu-Al-Mn shape memory alloy. Physics Status Solidi A. 2006;203(5):825-830.

8. Recarte V, Pérez-Sáez RB, San Juan J, Bocanegra EH, Nó $\mathrm{ML}$. Influence of $\mathrm{Al}$ and $\mathrm{Ni}$ concentration on the martensitic transformation in $\mathrm{Cu}-\mathrm{Al}-\mathrm{Ni}$ shape-memory-alloys. Metallurgical and Materials Transactions A. 2002;33(8):2581-2591.

9. Zak G, Prader P, Kneissl AC. Gefüge und Eigenschaften von Cu-Al-Mn-Form-gedächtnislegierungen. Metall. 1995;49(6):415418

10. Sutou Y, Omori T, Kainuma R, Ishida K. Ductile Cu-Al-Mn based shape memory alloys: general properties and applications. Materials Science and Technology. 2008;24(8):896-901.

11. Kainuma R, Satoh N, Liu XJ, Ohnuma I, Ishida K. Phase equilibria and Heusler phase stability in the $\mathrm{Cu}$-rich portion of the Cu-Al-Mn system. Journal of Alloys and Compounds. 1998;266(1-2):191-200.

12. Gouda ES, Ahmed E, Tawfik N. Melting and Corrosion Behavior of Al-9Zn Based Alloys with $\mathrm{Cu}$ and Mg Additions. Materials Sciences and Applications. 2011;2:469-475.

13. Kumar P, Jain AK, Hussain S, Pandey A, Dasgupta R. Changes in the properties of $\mathrm{Cu}-\mathrm{Al}-\mathrm{Mn}$ shape memory alloy due to quaternary addition of different elements. Matéria (Rio J). 2015;20(1):284-292.

14. Matsushita K, Okamoto T, Okamoto T. Effects of manganese and ageing on martensitic transformation of $\mathrm{Cu}-\mathrm{Al}-\mathrm{Mn}$ alloys. Journal of Materials Science. 1985;20(2):689-699.

15. Obrado E, Mañosa L, Planes A. Stability of the bec phase of $\mathrm{Cu}-\mathrm{Al}-\mathrm{Mn}$ shape-memory alloys. Physical Review $B$. 1997;56(1):20-23.

16. Lopez-Ferreño I, Breczewski T, Ruiz-Larrea I, Lopez-Echarri A, Nó ML, San Juan J. Thermal treatments and transformation behavior of $\mathrm{Cu}-\mathrm{Al}-\mathrm{Be}$ shape memory alloys. Journal of Alloys and Compounds. 2013;577(Suppl 1):S463-S467.

17. Guilemany JM, Fernandez J, Zhang XM. TEM study on the microstructure of $\mathrm{Cu}-\mathrm{Al}-\mathrm{Ag}$ shape memory alloys. Materials Science and Engineering: A. 2006;438-440:726-729. 
18. Prado MO, Decorte PM, Lovey F. Martensitic transformation in Cu-Mn-Al alloys. Scripta Metallurgica et Materialia. $1995 ; 33(6): 877-883$.

19. Liu JL, Huang HY, Xie JX. Superelastic anisotropy characteristics of columnar-grained $\mathrm{Cu}-\mathrm{Al}-\mathrm{Mn}$ shape memory alloys and its potential applications. Materials \& Design. 2015;85:211-220

20. Sutou Y, Koeda N, Omori T, Kainuma R, Ishida K. Effects of ageing on bainitic and thermally induced martensitic transformations in ductile $\mathrm{Cu}-\mathrm{Al}-\mathrm{Mn}$-based shape memory alloys. Acta Materialia. 2009;57(19):5748-5758.

21. Göken J, Riehemann W. Thermoelastic damping of the low density metals AZ91 and DISPAL. Materials Science and Engineering: A. 2002;324(1-2):134-140.

22. Sedlák P, Seiner H, Landa M, Novák V, Šittner P, Mañosa LI. Elastic constants of bcc austenite and $2 \mathrm{H}$ orthorhombic martensit in CuAlNi shape memory alloy. Acta Materialia. 2005;53(13):3643-3661.
23. Yasuda T, Tani D, Nishino H, Yoshida K. Evaluation of two types of martensitic transformation in $\mathrm{Cu}-\mathrm{Al}-\mathrm{Ni}$ shape memory alloy single cristal by acoustic emission waveform analysis. Journal of Acoustic Emission. 2006;24:153-160.

24. Bidaux JE, Ahlers M. The stabilization of $18 \mathrm{R}$ and $2 \mathrm{H}$ martensite in $\mathrm{Cu}-\mathrm{ZnAl}$ alloys with an electron concentration $\mathrm{e} / \mathrm{a}=1.534$. Journal de Physique IV Colloque: C. 1991;4:211216.

25. Cheniti H, Bouabdallah M, Patoor E. High temperature decomposition of the $\beta 1$ phase in a $\mathrm{Cu}-\mathrm{Al}-\mathrm{Ni}$ shape memory alloy. Journal of Alloys and Compounds. 2008;476(1-2):420424 .

26. Khalil Allafi J, Ren X, Eggeler G. The mechanism of multistage martensitic transformations in aged Ni-rich NiTi shape memory alloys. Acta Materialia. 2002;50(4):793-803.

27. Riehemann W. Metallische Werkstoffe mit extremer innerer Reibung und deren Messung. Clausthal-Zellerfeld: Clausthal Papierflieger; 1994. 